\title{
Computational Analysis of the Aerodynamic Performance of a Long-Endurance UAV
}

\section{Wonjin Jin*}

Dept. of Aviation Maintenance Engineering, Far East University, Chungbuk 369-700, Korea

\section{Yung-Gyo Lee**}

Aerodynamics Division, Korea Aerospace Research Institute, Daejeon 305-333, Korea

\begin{abstract}
This paper presents the computational aerodynamic analysis of a long-endurance UAV that was developed by the Korea Aerospace Research Institute (KARI), named EAV-2. EAV-2 is a technical demonstrator of aerodynamically efficient design, as well as a hybrid electric-propulsion system for future long-endurance UAVs. We evaluated the aerodynamic characteristics of six low-Reynolds number airfoils, using a panel method code, XFOIL, to select an optimal airfoil for the long-endurance mission of EAV-2. The computational results by a CFD code, FLUENT, suggested that the aerodynamic performance of EAV2 would be notably improved after adopting SG6043 airfoil, and modifying the fuselage design. This reduced the total drag by $43 \%$, compared to that of a previous KARI model, EAV-1, at the target lift of $C_{L}=1.0$. Also, we achieved a drag reduction of approximately $14 \%$ by means of the low-drag fuselage configuration.
\end{abstract}

Key words: Long endurance, UAV, Low-Reynolds number airfoils, CFD

\section{Nomenclature}

$\begin{array}{ll}A R & \text { Aspect ratio, } \\ b & \text { Wing span, } m \\ C & \text { Chord length of airfoil, } m \\ c_{d} & \text { Drag coefficient of airfoil, } ~ \\ c_{d_{\min }} & \text { Minimum drag coefficient of airfoil, } ~ \\ C_{D} & \text { Drag coefficient of aircraft, } ~ \\ c_{l} & \text { Lift coefficient of airfoil, } \sim \\ c_{l_{\max }} & \text { Maximum lift coefficient of airfoil, } \sim \\ C_{L} & \text { Lift coefficient of aircraft, } \sim \\ C_{L_{\max }} & \text { Maximum lift coefficient of aircraft, } ~ \\ C_{m_{\alpha}} & \text { Pitching moment coefficient of aircraft at } 25 \% \\ & \text { chord, } \text { rad }^{-1} \\ H & \text { Overall height of aircraft, } m \\ L & \text { Overall length of aircraft, } m \\ \text { Re } & \text { Reynolds number, } ~\end{array}$

$R_{L E} \quad$ Radius of airfoil leading edge, $m$

$t_{\max } \quad$ Maximum thickness of airfoil, $m$

$S_{W} \quad$ Wing area, $m^{2}$

$V \quad$ Velocity, $m / s$

$y^{+} \quad$ Non-dimensional wall distance,

$\alpha \quad$ Angle of attack, deg.

$\alpha_{\text {stall }} \quad$ Stall angle of attack, deg.

$\Gamma \quad$ Dihedral angle, deg.

$\lambda \quad$ Taper ratio,

\section{Introduction}

In recent years, interest in Long-endurance Unmanned Aerial Vehicles (UAVs) has increased, due to their usefulness in various applications, such as strategic reconnaissance, telecommunication links, metrological research, forest fire detection, and disaster monitoring. Therefore, a long-
This is an Open Access article distributed under the terms of the Creative Commons Attribution Non-Commercial License (http://creativecommons.org/licenses/by$\mathrm{nc} / 3.0 /$ which permits unrestricted non-commercial use, distribution, and reproduction in any medium, provided the original work is properly cited. (c) * Assistant Professor, Corresponding author: jwonjin@gmail.com

** Principal Researcher, lyg@kari.re.kr 
endurance UAV is considered as one of the future air vehicle systems that can support the roles of satellites, with relatively low operation and maintenance costs.

Studies have been conducted to determine suitable configurations, as well as effective propulsion systems, for long-endurance UAVs. ${ }^{1-2}$ It is known that the electricity from fuel cells and solar cells is an appropriate power source for long-endurance flight. Fuel cells have a higher energy density compared to ordinary batteries, and the electricity can be recharged from solar cells during daytime flight. Those energy-generating characteristics can contribute to UAV long-endurance flights that continue for several days. Also, propulsion systems with fuel cells and solar cells are considered eco-friendly, since they do not cause a problem of $\mathrm{CO}_{2}$ or harmful gas emission. ${ }^{3}$ The Korea Aerospace Research Institute (KARI) has also been studying low-drag aircraft designs and effective propulsion systems that can be incorporated in long-endurance UAV systems. KARI previously developed $E A V-1^{4}$ (Fig. 1), and this small-size propeller driven UAV was designed to test an electric propulsion system with hydrogen-fuel cells. The next model, $E A V-2$, is characterized by a bigger fuselage for more hydrogen-fuel cell loading, and wider wings for mono-crystalline silicon solar cell installation (Fig. 2). EAV2 is the first long-endurance UAV with a hybrid electricpropulsion system in Korea, and is powered by fuel cells and solar cells. Test flights allow the problems of the hybrid propulsion system to be identified, in order to improve the system design and operational technologies. The design of low-drag configurations for the long-endurance mission is also important. EAV-2 is equipped with a high-aspect ratio wing $(A R=20)$ to reduce the induced drag, and to provide sufficient area for the required number of solar cell panels. Other than the aspect ratio, many design parameters of aircraft must be exhaustively examined for low drag and low-power consumption during long-endurance flight. In particular, the selection of an optimum airfoil for EAV-2 in the low speed/Reynolds number flow regime is critical. Therefore, in this study, we computationally investigated the aerodynamic characteristics of several high-performance low-Reynolds number airfoils, to determine the optimum airfoil for this solar-powered long-endurance UAV. Also, we evaluated the aerodynamic performances of the low-drag fuselage configurations, through CFD techniques.

\section{Computational Methodologies}

We analyzed the aerodynamic characteristics of airfoils using $X F O I L,{ }^{5}$ a panel method code for airfoil design at the low-speed regime. To validate the XFOIL prediction results, we calculated the aerodynamic coefficients of low-Reynolds number airfoils, SD7032 and SG6043, by XFOIL at Re $=2.0 \times 10^{5}$, and compared the results to the experimental data from the low-speed wind tunnel, ${ }^{6,7}$ as presented in Fig. 3. We can see from the figure that the aerodynamic characteristics of these two airfoils are relatively well predicted by XFOIL. Also, the predicted drag level of the airfoils can be acceptable, considering the simplified viscous model in the panel method code.

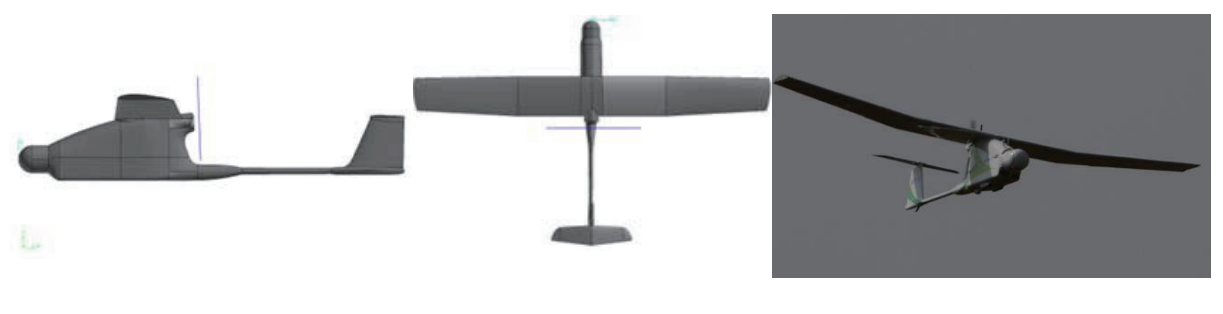

(a) Side view

(b) Top view

(c) Flight test

Fig. 1. KARI's EAV-1, the fuel-cell powered UAV

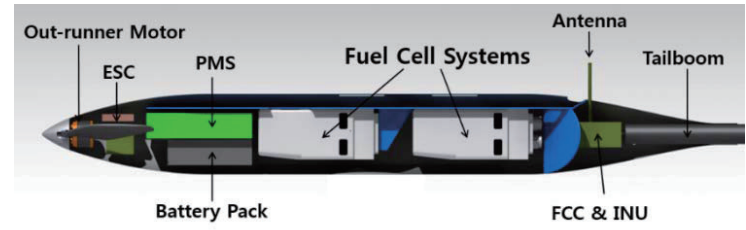

(a) Fuel cell systems inside the fuselage

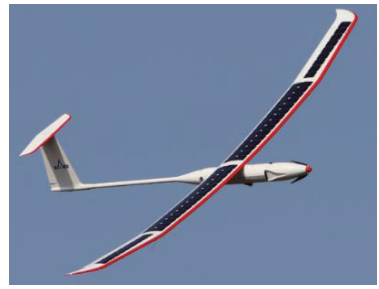

(b) Solar cell panels on the wing

Fig. 2. EAV-2's hybrid electric-propulsion system 
We used a commercial CFD code, $F L U E N T^{8}$, to simulate the aerodynamic performance of full-scale aircraft models. Pre-processing tools for surface and volume mesh generations were GAMBIT, ${ }^{9}$ and $T$-GRID,${ }^{10}$ respectively. For the proper near-wall mesh resolution, the non-dimensional wall distance was defined as $y^{+}<5$, and the height of the first mesh cell from the surface was set to be $2 \times 10^{-4} \mathrm{~m}$, based on the designed cruise speed of EAV-2. Also, a total of 12 mesh-layers were constructed within the boundary layer, for more realistic simulation of the viscosity effects over the aircraft surfaces. Therefore, the total size for structured and unstructured meshes was approximately 20 million cells. Figure 4 (a) provides a graphic example of surface meshing for EAV-2. The modeling of a propeller was omitted to simplify the simulations; therefore, the effects of propeller installation and slipstream were not considered. Velocityinlet and pressure-outlet boundary conditions were applied to the $C$-type far-field domain shape, which was suitable to simulate the variation of angle of attack, as Fig. 4 (b) shows. The Reynolds number of the free-stream flow was $=2.8 \times 10^{5}$, based on the wing root-chord length. We utilized the Spalart-Allmaras turbulent model, due to its popularity in many aerospace applications, given its reliability and speedy calculation. Turbulent intensity and turbulent length scale were set as $0.1 \%$ and $0.01 \mathrm{~m}$, respectively, based on the turbulence level of the KARI Subsonic-Wind Tunnel. The calculations for the lift, drag, and pitching moment were continued, and monitored until the value of each coefficient changed by less than approximately $0.5 \%$. The parallelcomputing systems in the Aerodynamics Division Lab in KARI were dedicated to those simulations and computations.

We validated a FLUENT analysis with the fore-mentioned computational methodologies for EAV-1 aerodynamic performance. The aerodynamic characteristics during the actual flight test of EAV- ${ }^{11}$ are indicated on the FLUENT prediction results shown in Fig. 5. Lift and drag coefficients were measured based on the actual steady level-turning flight with a given speed and angle of attack, which we also applied to a CFD simulation. Figure 5 (a) shows that the lift characteristic is properly predicted by the FLUENT calculation, whereas some discrepancy (30\%) is observed for the drag characteristics, as Fig. 5 (b) shows. The reason is that the factors producing additional drag in the actual flight, such as propeller slipstream effects, deflection of control surfaces for turning flight, and installation of external equipment, were not considered for CFD, in order to simplify the computational procedure. After adding up those additional drags, as estimated by the aircraft design software, Advanced Aircraft Analysis (AAA), ${ }^{12}$ the discrepancy was reduced to about $8 \%$.

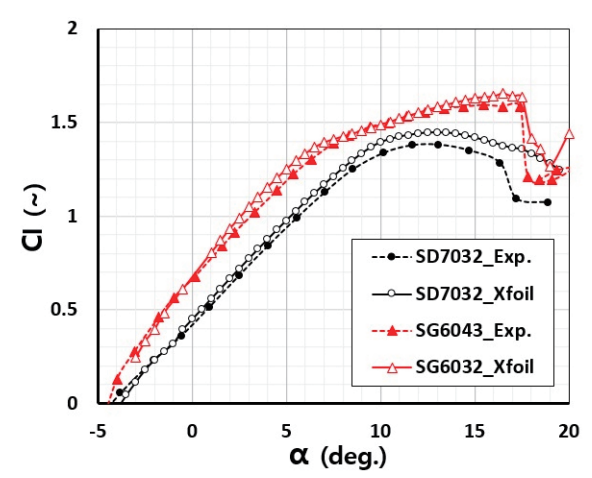

(a) Lift curve slop

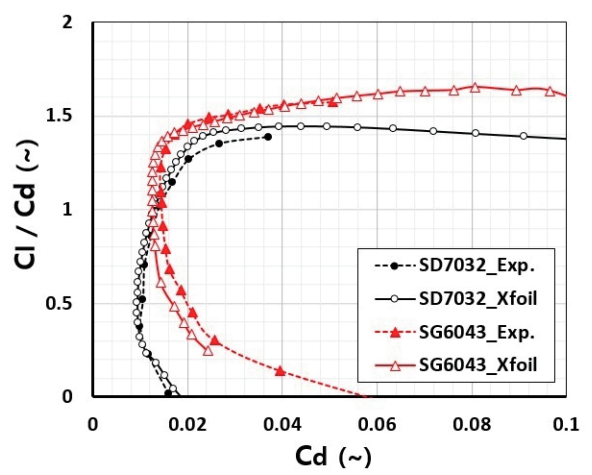

(b) Drag polar

Fig. 3. Validation of XFOIL calculation results with experimental data ${ }^{6,7}\left(\operatorname{Re}=2.0 \times 10^{5}\right)$

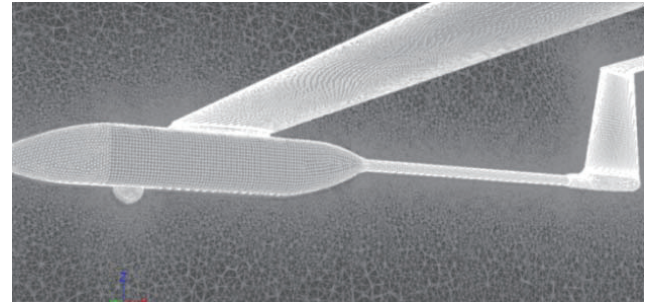

(a) Surface mesh for EAV-2

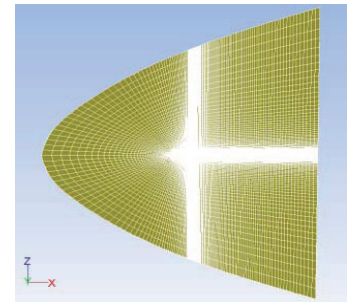

(b) C-type far-field domain

Fig. 4. Mesh generation for CFD analysis 


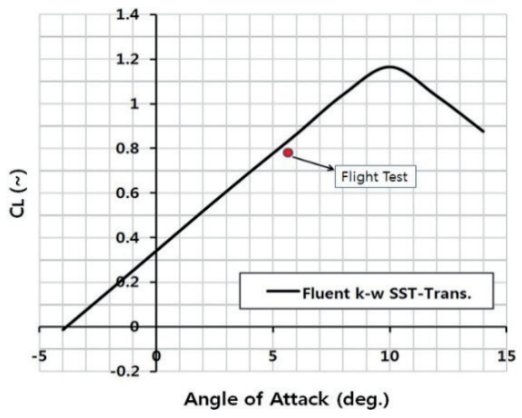

(a) Lift curve slope

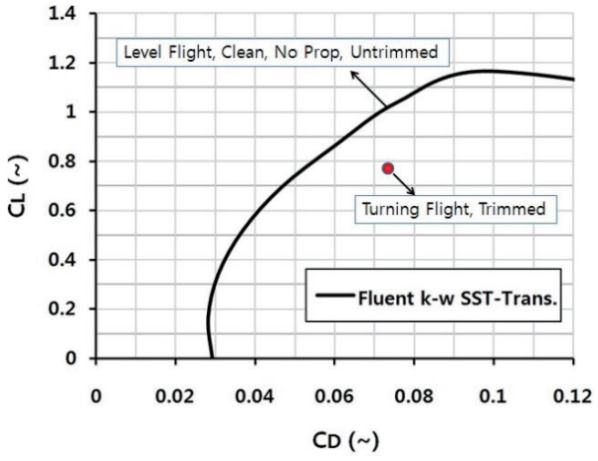

(b) Drag polar

Fig. 5. Validation of CFD methodologies with flight test data ${ }^{11}\left(E A V-1, R e=3.1 \times 10^{5}\right)$

\section{Results and Discussion}

\subsection{Low Reynolds Number Airfoils}

High-lift devices are not considered for EAV-2 to minimize the weight; therefore, EAV-2 must have the wing and airfoil that produce adequate lift force during the take-off and landing. In addition, generation of the least drag force at cruise condition is critical for long-endurance flights. In that sense, the design or selection of an airfoil, optimized for all of EAV-2's flight conditions, must be performed through careful consideration and analysis. In general, the drag increases proportionally to the increase of lift. Therefore, a target lift value has to be set, to compare the drag characteristics of the various airfoils. In this study, we defined the target lift coefficient as $c_{l}=1.0$, since the designed cruise lift of EAV-2

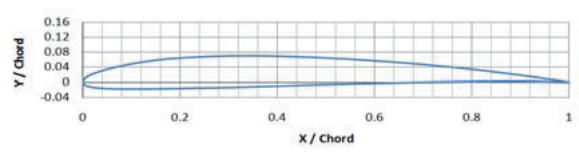

(a) SD7032M

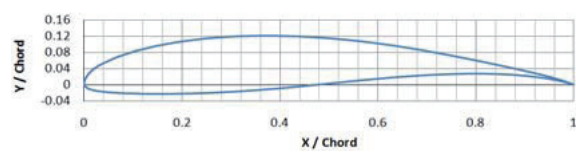

(c) FX63-137

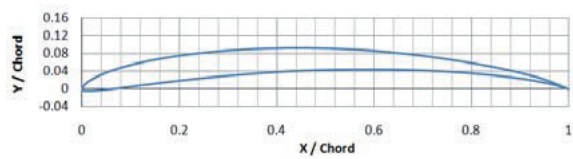

(e) E16 is $C_{L}=0.8$, and this approximately corresponds to the airfoil's lift of $c_{l}=1.0$. The main objective of our analysis is therefore to find the airfoil of least drag near $c_{l}=1.0$. Considering the fact that EAV-2 flies at a low speed below $20 \mathrm{~m} / \mathrm{s}$, six typical high-lift low-Reynolds number airfoils were investigated: SD7032M, SG6043, FX63-137, S1223, E61, and GOE15. In particular, SD7032M, a modified version of SD7032, was previously used for EAV-1. Others are known as highperformance airfoils that are popularly used for small-scale UAVs, low-speed gliders, sailplanes, and human-powered aircraft. In particular, SG6043 was originally designed for variable-speed wind turbines. ${ }^{7}$

Figure 6 shows the geometrical information of those airfoils. From the figure, it can be seen that the airfoils with the highest and lowest thickness ratio are FX63-137 and E61, respectively; and the greatest and smallest amount of

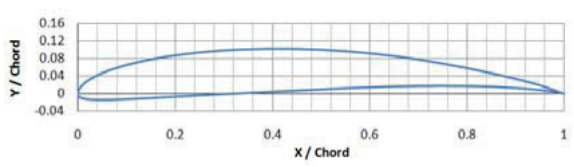

(b) SG6043

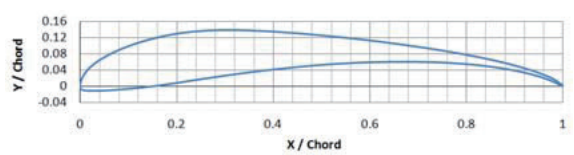

(d) $\mathrm{S} 1223$

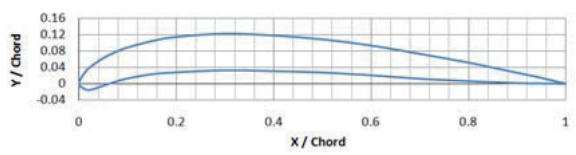

(f) GOE 15

Fig. 6. Geometries of considered low Reynolds number airfoils for EAV-2 
camber can be seen with S1223 and SD7032M, respectively.

We analyzed the lift characteristics of each airfoil by using XFOIL, and Fig. 7 (a) presents the results. The Reynolds number based on the airfoil chord length is about $\mathrm{Re}=2.2 \times 10^{5}$. We can see that all airfoils have better lift characteristics with higher $c_{l_{\max }}$ and $\alpha_{\text {stall }}$, compared to the airfoil of EAV-1, SD7032M. In particular, S1223 produces lift force of up to $c_{l_{\max }}=2.2$, and the other airfoils also generate relatively high $c_{l_{\max }}$. Furthermore, SG6043, FX63-137, and GOE15 show a stall delay, maintaining maximum lift with increase of the angle of attack.

Figure 7 (b) shows the drag characteristics. The lowest $c_{d_{\min }}$ is produced by SD7032M ( $\left.c_{d_{\min }} \sim 0.008\right)$, and $c_{d_{\min }}$ of GOE15 is more than twice as high as that of SD7032M. The values $c_{d_{\min }}$ of SG6043, FX63-137, and E61 are relatively low, compared to those of S1223 and GOE15. Also, those three airfoils maintain the minimum drag, $c_{d_{\min }}$ over a wide range of lift $\left(0.8<c_{l}<1.5\right)$. Therefore, the drag characteristics of SG6043, FX63-137, and E61 are favorable, since those airfoil produce the minimum drag at the target lift of $c_{l}=1.0$. As mentioned above, S1223 produces the highest lift force; however, the drag from the airfoil is significant. Furthermore, manufacturing difficulties and geometrical distortion can be expected with S1223, due to its high-cambered sharp trailing edge shape, as Fig. 6 (d) shows. A tiny geometrical distortion of airfoil caused by manufacturing error can result in a significant reduction of aerodynamic performance. E61 is also characterized by a thin and high-cambered shape; therefore, similar problems might be produced, in spite of a relatively low drag level. In particular, a thin airfoil such as E61 can cause weight increase from the structural reinforcements. GOE15 has stall delay characteristics as well; however, it induces the highest $c_{d_{\min }}$.

Considering the characteristics of the candidate airfoils in terms of aerodynamic performance, manufacturability, and weight increase, the number of candidates can be reduced to two: SG6043 and FX63-137. Both airfoils generate relatively

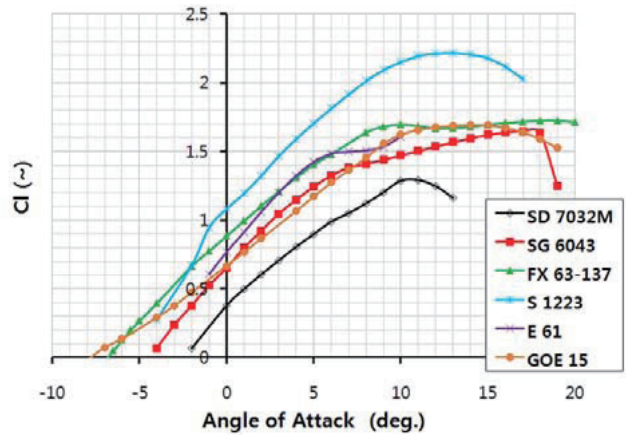

(a) Lift curve slops high-lift force with the stall delay characteristic, maintaining the least drag at the target lift of $c_{l}=1.0$. The drag of SG6043 and FX63-137 are $c_{d}=0.0125$ and 0.0146, respectively. Also, they have good manufacturability, due to their moderate airfoil-camber and thickness, without the burden of structural weight increase.

\subsection{Transition Point Sensitivity Analysis}

We evaluated transition point sensitivity to the airfoil drag characteristic. A transition point indicates the location where transition from a laminar to turbulent flow occurs. Usually, the transition type is divided into natural and forced transitions. A closer transition point to the leading edge of a wing means a wider area for turbulent flow over the wing surface, which generates more viscous drag. Minor airfoil shape change, due to wing contamination from insect residue or ice accretion, may cause a forced transition, while a natural transition is attributed to the airfoil shape itself. Small distortion of the airfoil shape resulting from the installation of solar cells on the EAV-2 wing may also induce forced transition, and this can contribute to drag increase. Therefore, it is important to check the effect of forced transition on the selected airfoils. In this study, the forced transition is assumed to be located in the 5\% chord of the upper and lower surfaces of SG6043 and FX63-137 airfoils. The assumption of 5\% transition can be considered as a relatively severe case. We calculated the drag coefficients with $5 \%$ transition using XFOIL, and compared the results to natural transition cases, as Fig. 8 shows. At the target lift of $c_{l}=1.0$, the drag rises up 70 and 57 counts for SG6043 and FX63-137, respectively; and these values correspond to $55 \%$ and $40 \%$ increases. Usually, this is due to the fact that a forced transition commonly reduces lift force level, much more than the drag force level. Therefore, when drag coefficients are compared at a certain lift level, for example $c_{l}=1.0$, the drag level seems to increase. Although

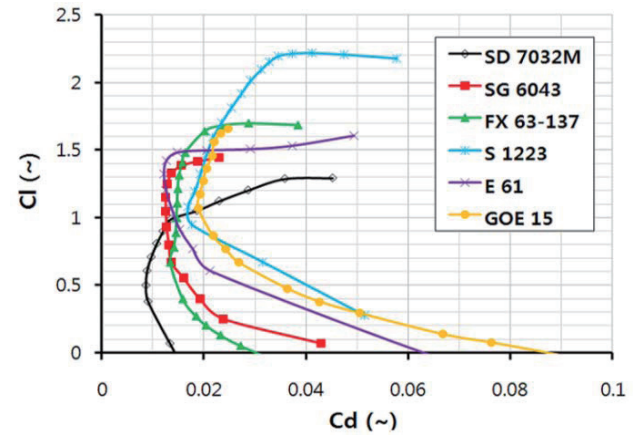

(b) Drag polar

Fig. 7. Comparison of airfoil aerodynamic characteristics (XFOIL, $R e=2.2 \times 10^{5}$ ) 
the decreased lift can result in increased drag, drag increases of over $40 \%$ are still substantial. An experimental result also reveals that the aerodynamic performance of high-lift lowReynolds number airfoils suffers from forced transition by the addition of simulated roughness. ${ }^{13}$ Therefore, complete surface finishing for the solar cell-installed wing must be performed. Also, further study of the forced transition is required, to analyze more detailed effects of the solar cell installation on the aerodynamic performance of aircraft.

\subsection{Full-scale CFD Analysis for Airfoil Selection}

To select the optimum airfoil that produces the best performance for EAV-2, we carried out CFD analysis for a fullscale aircraft model equipped with the candidate airfoils. We implemented SD7032M (EAV-1 airfoil), SG6043, and FX63137 airfoils to the defined wing configuration $\left(S_{W}=1.98 \mathrm{~m}^{2}\right.$, $b=6.4 \mathrm{~m}$, and $A R=20$ ), and named each aircraft model as EAV-1A, EAV-1B, and EAV-1C, respectively. Therefore, EAV$1 \mathrm{~A}, \mathrm{~B}$, and $\mathrm{C}$ have the same aircraft configuration, except for the airfoils. The fuselage shape is basically a scaled-up version of EAV-1. We defined the overall size, layout, and configuration/size of other components, such as vertical and horizontal stabilizers, according to a conceptual aerodynamic design procedure, using AAA.${ }^{12}$ Figure 9 shows the side and top views of $\mathrm{EAV}-1 \mathrm{~A} / \mathrm{B} / \mathrm{C}$.

Figure 10 (a) presents the CFD results for the lift characteristics of EAV-1A, B, and C. We defined the Reynolds

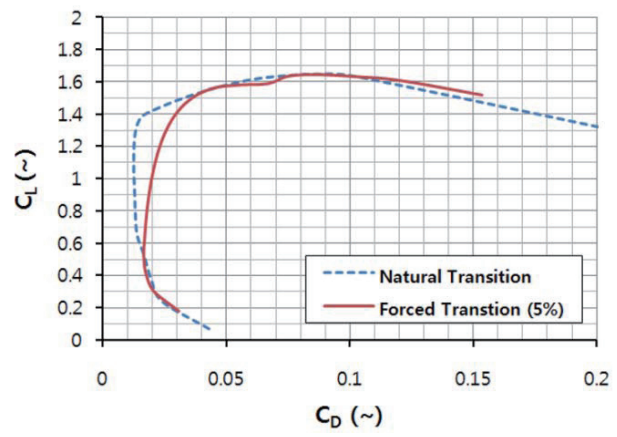

(a) SG6043 number, $\mathrm{Re}=2.8 \times 10^{5}$, on the basis of the wing chord length and flight velocity of $V=11 \mathrm{~m} / \mathrm{s}$. In comparison with EAV1A with SD7032M, EAV-1B and C with SG6043 and FX63137, respectively, produce considerably more lift force. The maximum lift of EAV-1A is $C_{L_{\max }}=1.3$, while those of EAV-1B and $C$ are about $C_{L_{\max }}=1.7$, and the increment is approximately $30 \%$. Also, compared to EAV-1 with smaller wing area $\left(S_{W}=0.68 \mathrm{~m}^{2}\right)$, the maximum lift has increased by about $44 \%$. However, the two aircraft with SG6043 and FX63137 show no significant difference in their lift characteristics.

Figure 10 (b) shows the CFD result for the drag coefficient of each aircraft. The result suggests that those three aircraft models produce similar amounts of drag (about $C_{D}=0.05$ ) at $C_{L}=0.8 \sim 1.0$. However, EAV-1B and C with SG6043 and FX63137 maintain relatively low drag at the higher lift range, until $C_{L}=1.4 \sim 1.6$; whereas, EAV-1A enters a stall from $C_{L}=1.2$. In addition, the CFD analysis for longitudinal stability of the three aircraft shows that the pitching moments of EAV-1A, B, and C based on $25 \%$ mean chord length are $C_{m_{\alpha}}=-3.02,-3.53,-3.55$ $\mathrm{rad}^{-1}$, respectively. Considering that the pitching moments of conventional aircraft, except fighters, are within the range of $C_{m_{\alpha}}=-0.6 \sim-1.6 \mathrm{rad}^{-1},{ }^{14} \mathrm{EAV}-1 \mathrm{~A} / \mathrm{B} / \mathrm{C}$ have an excessive tendency for nose-down. In particular, an experimental analysis showed that high-lift airfoils, such as SG6043, have fairly high-pitching moments, due to their high-lift and aftloaded characteristic. ${ }^{7}$ This tendency must be adjusted by the additional modification of aircraft configuration, such as the location and size of the horizontal stabilizer.

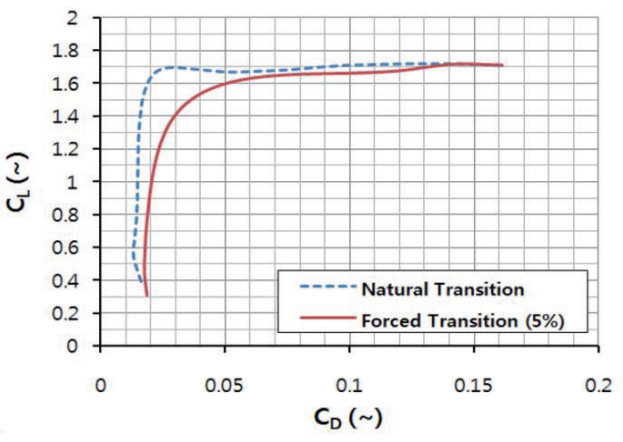

(b) FX63-137

Fig. 8. Transition point sensitivity analysis for airfoil drag (XFOIL, Re $\left.=2.2 \times 10^{5}\right)$

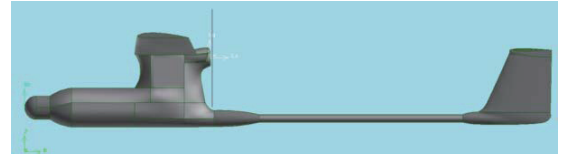

(a) Side view

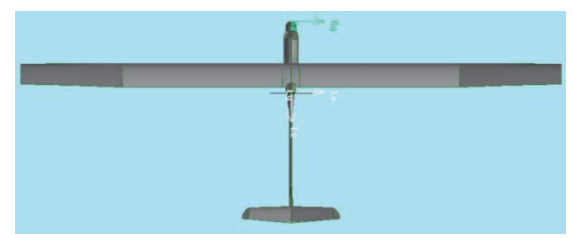

(b) Top view

Fig. 9. Configuration of EAV-1A/B/C 
In conclusion, XFOIL and CFD analyses confirm that both SG6043 and FX63-137 show relatively superior characteristics in aerodynamic performance, compared to EAV-1's airfoil (SD7032M) and other candidate airfoils. SG6043 and FX63137 are almost similar in terms of aerodynamic performance, even though they differ geometrically. However, we finally selected SG6043 as an optimal airfoil for EAV-2's long-endurance mission, since it has more advantages in manufacturability, with a thicker trailing edge than FX63137, as Figs. 6 (b) and (c) show.

\subsection{Low-drag Fuselage Design}

In the previous chapter, the fuselage configuration of $\mathrm{EAV}-1 \mathrm{~A} / \mathrm{B} / \mathrm{C}$ is similar to that of EAV-1. This is mainly characterized by a semi-spherical nose for a surveillance system mount, and perpendicular part to the airflow between the fuselage and wing, as Fig. 9 shows. This pusher-type configuration is usually not streamlined; and it induces more profile drag, in spite of some aerodynamic advantages, such as the attachment of airflow over the wing and fuselage. The reduction of propeller efficiency is another disadvantage of the pusher-type layout. We therefore changed this configuration to tractor-type for drag reduction. Also, we redesigned the fuselage to a streamlined shape, and expect a considerable profile drag reduction. In addition, the cross-sectional shape of the fuselage is rectangular,

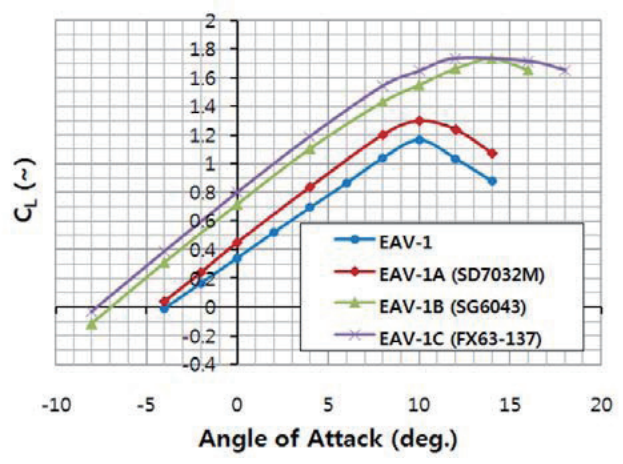

(a) Lift curve slopes to accommodate the fuel cell system of a parallelepiped configuration. Minimization of the fuselage volumetric size to reduce additional profile drag was possible through the effective design of internal equipment layout. As mentioned above, the previous aircraft design for EAV-1A/B/C has the excessive tendency of nose down. To mitigate this tendency, we reduced the overall length and horizontal tail area by $5 \%$ and $20 \%$, respectively. We also increased the vertical stabilizer area by $25 \%$, to provide additional lateral and directional stabilities. Figure 11 shows the final design of EAV-2. The overall dimensions are as follows: $L=2.6 \mathrm{~m}, H=0.6 \mathrm{~m}, b=6.4 \mathrm{~m}$, and $S_{W}=1.98 \mathrm{~m}^{2}$. SG6043, the selected airfoil, is applied to the root and tip of the wing, and NACA0010-34 and NACA001234 are the airfoils for the horizontal and vertical stabilizers, respectively. The taper ratio of the wing is $\lambda=0.8$, and the aspect ratio is $A R=20$. This high-aspect ratio will contribute to reducing the wing-induced drag. We apply the dihedral angle of $\Gamma=4^{\circ}$ at $63 \%$ of the spanwise location to enhance the lateral stability. Also, the T-tail type stabilizer has advantages of increasing stabilizer effectiveness at the low-speed regime.

Figure 12 shows the CFD results for the aerodynamic performance of EAV-1B and EAV-2. Note that EAV-1B has the same airfoil and wing planform as EAV-2; however, the fuselage configuration and overall size are different, as Figs. 9 and 11 show. Figure 12 (a) indicates that EAV-1B and EAV2 produce highly similar patterns in lift variation with the angle of attack. This is due to the fact that both aircraft share

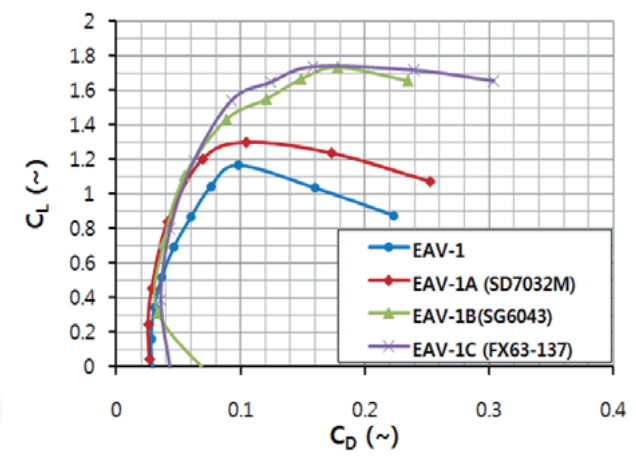

(b) Drag polar

Fig. 10. Comparison of aircraft aerodynamic characteristics (FLUENT, Re $=2.8 \times 10^{5}$ )

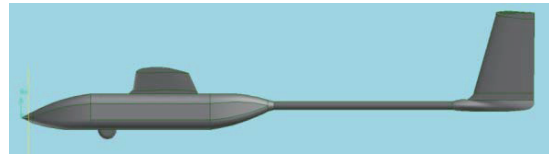

(a) Side view

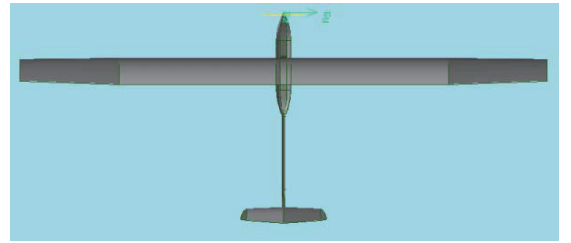

(b) Top view

Fig. 11. Configuration of EAV-2 
commonalities in airfoil and wing geometry, and most of the lift force is generated from the wing. For EAV-1B and EAV2 , the lift generation from the fuselage is small compared to the wings; therefore the contribution of fuselage to the lift characteristics is not significant.

However, the pitching moments based on $25 \%$ wing mean chord length differ. We can see from Fig. 12 (b) that the previous problem of excessive nose-down is mitigated by the new EAV-2 design: decreased overall length, and reduced horizontal-stabilizer area. According to the CFD results, the pitching moment of EAV-1B is $C_{m_{a}}=-3.53 \mathrm{rad}^{-1}$, while that of EAV-2 is $C_{m_{\alpha}}=-1.84 \mathrm{rad}^{-1}$; therefore, the pitching moment increases by approximately $48 \%$.

Figure 12 (c) presents the drag polars of EAV-1B and EAV2. As expected, we can see that the drag generation notably decreases for EAV-2, mainly due to the change of fuselage configuration. To more accurately measure drag reduction at the long-endurance cruise condition, we produce the plot for $C_{L}^{1.5} / C_{D}$ versus angle of attack by the Breguet range equation and CFD method, as Fig. 12 (d) shows. The result indicates that maximum-endurance occurs at the condition of $\left(C_{L}^{1.5} /\right.$ $\left.C_{D}\right)_{\max }=21$ and 25 for EAV-1B and EAV-2, respectively, and the corresponding angles of attack are $\alpha=4.8^{\circ}$ and 5.5 . Fig. 12

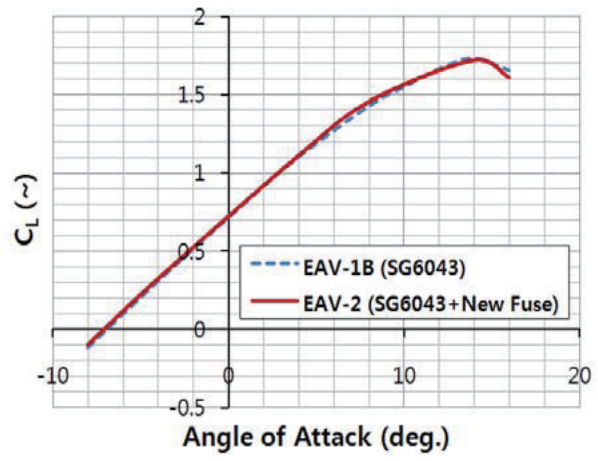

(a) Lift curve slope

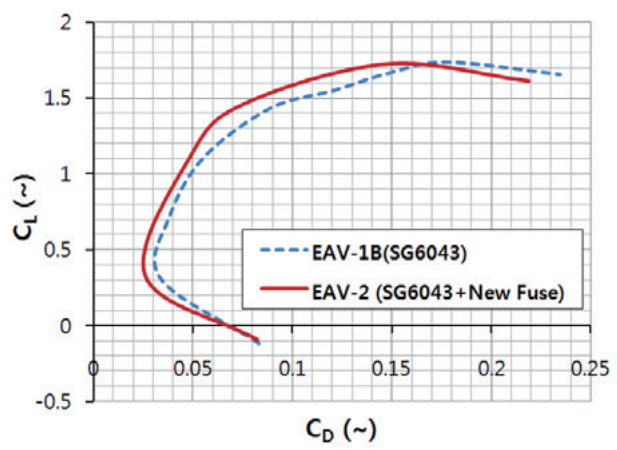

(c) Drag polar (a) suggests that the lift coefficients at these angles of attack, in other words, the lift coefficients at maximum-endurance cruise condition, are $C_{L}=1.2$ and 1.27 for EAV-1B and EAV-2, respectively. However, we need to consider the stall margin, since after these lift ranges, aircraft are apt to enter the stall with sudden and substantial increase of drag. Therefore, the actual lift condition for maximum-endurance (or long-endurance) should be conservatively determined. In that sense, we reduce the lift condition to $C_{L}=1.0$, and this value was originally the target-lift condition from the initial design stage. Now we can see from Fig. 12 (c) that the drag generation of EAV-1B is about $C_{D}=0.050$ at the maximum-endurance condition of $C_{L}=1.0$, whereas that of EAV-2 is $C_{D}=0.043$. Therefore, the total drag reduction, after applying the low-drag design to EAV-2, is about $14 \%$. Compared to EAV-1, a smaller pusher-type UAV, the drag significantly decreases by up to $43 \%$ since EAV-1's drag generation is $C_{D}=0.076^{4}$ at $C_{L}=1.0$.

\section{Conclusion}

In this study, the computational analyses of the aerodynamic characteristics of EAV-2, KARI's long-

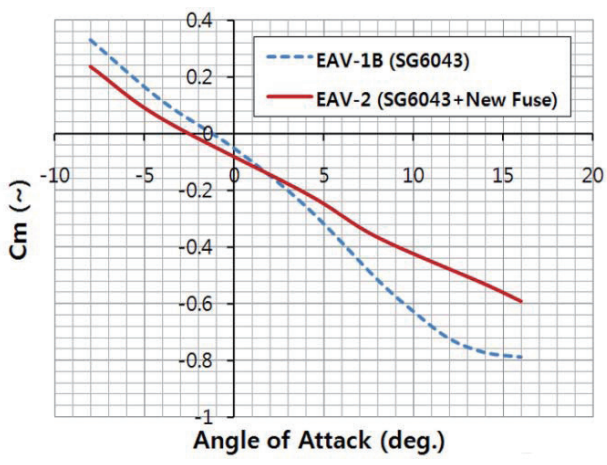

(b) Pitching moment curve

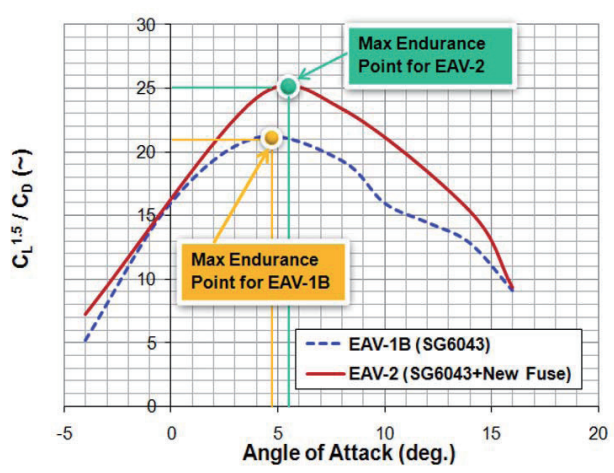

(d) Maximum endurance condition

Fig. 12. Aerodynamic performance of EAV-2 (FLUENT, Re $=2.8 \times 10^{5}$ ) 
endurance UAV, were carried out using the panel method and CFD code. The main objective of this analysis was to evaluate the most appropriate airfoil and low-drag fuselage design that will improve the aerodynamic performance of EAV-2 in long-endurance missions. The results revealed that SG6043, originally designed for wind-turbines, was the best, due to its stall delay characteristic, lower-drag generation, and manufacturability. In addition, we changed the pushertype layout to the tractor-type, and re-designed the fuselage, in order to reduce the profile drag. Consequently, the total drag decreased by $43 \%$ and $14 \%$ compared to EAV- 1 and the previous EAV-2 model (EAV-1B), respectively, at the target lift range of $C_{L}=1.0$. However, the drag level has substantially increased, under the assumption of a severe forced transition condition (transition in the 5\% chord of upper and lower surfaces). The installation of solar cells on the surface of EAV-2 wings and the resulting minor distortion of the airfoil/wing geometry may cause a similar forced transition. Therefore, we must perform extensive sensitivity analyses of possible forced transition due to the solar cell installation. Also, we should derived efficient solar cell installation and arrangement strategies that minimize the aerodynamic penalties of wing. In addition, we must verify the stability and control performances of the defined EAV2's aerodynamic design using aircraft design tools, such as AAA, ${ }^{12}$ or DATCOM. ${ }^{15}$

\section{Acknowledgement}

This research has been supported by the Korea Aerospace Research Institute (KARI), under the project, "System and Operational Technology Research for Electric Airplane (II)".

\section{References}

[1] G. Romeo, G. Frulla, E. Cestino, and G. Corsino, "HELIPLAT: Design, Aerodynamic and Structural Analysis of Long-Endurance, Solar-Powered Stratospheric Platform," Journal of Aircraft, Vol.41, No.6, 2004, pp. 1505-1520.

[2] C. L. Nickol, M. D. Guynn, L. L. Kohout, and T. A.
Ozoroski, "High Altitude Long Endurance Air Vehicle Analysis of Alternatives and Technology Requirements Development," AIAA Paper 2007-1050, Jan. 2007.

[3] J. W. Youngblood, T. A. Talay, and R. J. Pegg, "Design of Long Endurance Unmanned Airplanes Incorporating Solar and Fuel Cell Propulsion," AIAA Paper 84-1430, Jun. 1984.

[4] W. J. Jin, Y. G. Lee, C. W. Kim, S. M. Ahn, and D. S. Lee, "Computational Analysis of Aerodynamic Performance of a small-scale Electric Aerial Vehicle," Proceeding of the 2010 Korean Society for Aeronautical \& Space Sciences (KSAS) Fall Conference, Vol. 1, 2010, pp. 473-476.

[5] M. Drela and H. Youngren, XFOIL 6.94 User Guide, Massachusetts Institute of Technology, Cambridge, MA, URL: http://web.mit.edu/drela/Public/web/xfoil/, 2001.

[6] M. S. Selig, J. J. Guglielmo, A. P. Broeren, and P. Giguère, Summary of Low-Speed Airfoil Data, Vol. 1, Soar Tech Publications, Virginia Beach, 1995.

[7] C. A. Lyon, A. P. Broeren, P. Giguère, A. Gopalarathnam, and M. S. Selig, Summary of Low-Speed Airfoil Data, Vol. 3, Soar Tech Publications, Virginia Beach, 1998.

[8] ANSYS FLUENT Ver. 12 Software Package, Ansys Fluent Inc., Canonsburg, PA, USA.

[9] GAMBIT Software Package, Ver. 2.4.6, Ansys Fluent Inc., Canonsburg, PA, USA.

[10] TGRID Ver. 3.5, Ansys Fluent Inc., Canonsburg, PA, USA.

[11] Y. G. Lee, W. J. Jin, S. M. Ahn, and D. S. Lee, "Numerical and In-Flight Drag Estimation of a Small Electric Aerial Vehicle," Proceeding of the 2011 Korean Society for Aeronautical \& Space Sciences (KSAS) Fall Conference, Vol. 1, 2011, pp. 839-844.

[12] Advanced Aircraft Analysis Software Package, Ver. 3.2, DARCorporation, Lawrence, KS, USA.

[13] M. S. Selig and B. D.McGranahan, Wind Tunnel Aerodynamic Tests of Six Airfoils for Use on Small Wind Turbines, National Renewable Energy Laboratory Subcontractor Report, NREL/SR-500-34515, Oct. 2004.

[14] D. P. Raymer, Aircraft Design: A Conceptual Approach, the 4th edition, AIAA Education Series, AIAA Inc., Reston, 2006.

[15] J. E. Williams and S. R. Vukelich, “The USAF Stability and Control Digital Datcom,” AFFDL-TR-3032, Apr. 1979. 